Published in final edited form as:

Chem Res Toxicol. 2019 March 18; 32(3): 484-492. doi:10.1021/acs.chemrestox.8b00353.

\title{
Glutamine-451 Confers Sensitivity to Oxidative Inhibition and Heme-Thiolate Sulfenylation of Cytochrome P450 4B1
}

\author{
Matthew E. Albertolle ${ }^{\dagger}$, Hyun D. Song ${ }^{\ddagger}$, Clayton J. Wilkey ${ }^{\dagger}$, Jere P. Segrest ${ }^{\ddagger}$, F. Peter \\ Guengerich $^{\dagger}$ \\ tDepartment of Biochemistry, Vanderbilt University School of Medicine, Nashville, Tennessee \\ 37232-0146, United States \\ ¥Department of Medicine, Division of Cardiovascular Medicine, Vanderbilt University Medical \\ Center, Nashville, Tennessee 37232-6300, United States
}

\section{Abstract}

Human cytochrome P450 (P450) Family 4 enzymes are involved in the metabolism of fatty acids and the bioactivation of carcinogenic arylamines and toxic natural products, e.g. 4-ipomeanol. These and other drug metabolizing P450s are redox sensitive, showing a loss of activity resulting from preincubation with $\mathrm{H}_{2} \mathrm{O}_{2}$ and recovery with mild reducing agents (Albertolle, M.W. et al. (2017) J. Biol. Chem. 292, 11230-11242). The inhibition is due to sulfenylation of the hemethiolate ligand, as determined by chemopreoteomics and spectroscopy. This phenomenon may have implications in chemical toxicity and in observed disease-drug interactions, in which decreased metabolism of P450 substrates occurs in patients with inflammatory diseases (e.g., influenza, autoimmunity). Human P450 1A2 was determined to be redox insensitive. To determine the mechanism underlying the differential redox sensitivity, molecular dynamics (MD) simulations were employed using the crystal structure of rabbit P450 4B1 (PDB ID: 5T6Q). In simulating either the thiolate $\left(\mathrm{Cys}_{-} \mathrm{S}^{-}\right)$or the sulfenic acid $(\mathrm{Cys}-\mathrm{SOH})$ at the heme-ligation site, MD revealed Gln-451 in either an "open" or "closed" conformation, respectively, between the cytosol and heme-thiolate cysteine. Mutation to either an isosteric leucine (Q451L) or glutamate (Q451E) abrogated the redox sensitivity, suggesting that this "open" conformation allows for reduction of the sulfenic acid and thiolate religation to the heme iron. In summary, MD simulations suggest that Gln-451 in P450 4B1 adopts conformations that may stabilize and protect the heme-thiolate sulfenic acid; mutating this residue destabilizes the interaction, producing a redox insensitive enzyme.

\section{Graphical Abstract}

\footnotetext{
Address correspondence to: Prof. F. Peter Guengerich, Department of Biochemistry, Vanderbilt University School of Medicine, 638B Robinson Research Building, 2200 Pierce Avenue, Nashville, TN 37232-0146, Telephone: 1 (615) 322-2261, FAX: 1 (615) 343-0704, f.guengerich@vanderbilt.edu.

ASSOCIATED CONTENT

Supporting Information

The Supporting Information is available free of charge on the ACS Publications website at DOI: 10/1021/acs.chemres-tox. (TBA) Supporting Information, including basics of the simulation system, restrained regions of P450 4B1, RMSD of $\mathrm{C}_{\boldsymbol{a}}$ atoms for equilibration and production runs, Plots of number of waters within $5 \AA$ of Cys-448 sulfur, Ramachandran plots for Gly-450, Ramachandran plots for Gln-451, reduced CO-difference spectra of P450 4B1 WT and mutants, and topology file for Cys-SOH and Cy-SO.
} 


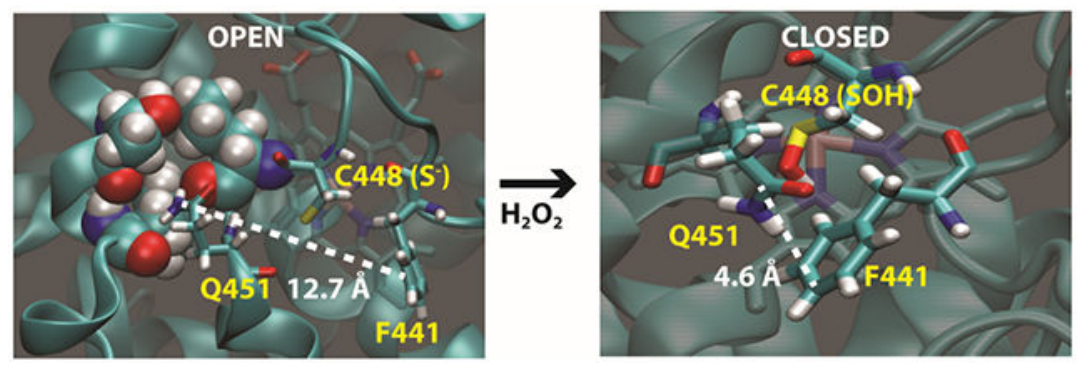

\section{INTRODUCTION}

Cytochrome P450 (P450, CYP) enzymes are important for the metabolism of both endogenous (e.g., steroids, vitamins, fatty acids) and exogenous (e.g., drugs, industrial chemicals, environmental toxicants) compounds. ${ }^{1}$ P450 4B1 catalyzes terminal $(\omega)$ and penultimate $(\omega-1)$ hydroxylation reactions of both endogenous and exogenous substrates. Noted exogenous substrates include the drug valproic acid, arylamines associated with bladder cancer (e.g., 2-aminofluorene, 2-aminoanthracene), and pneumotoxins (e.g., 4ipomeanol). ${ }^{2}$ No endogenous mammalian substrate has been reported, but P450 4B1 does hydroxylate medium-length chain saturated fatty acids (i.e., lauric acid) and alkanes at the $\omega$ and $\omega-1$ positions. ${ }^{3} \mathrm{P} 4504 \mathrm{~B} 1$ is an extrahepatic enzyme expressed mainly in the lung but also at low levels in the kidney, heart, digestive tract, and several other tissues. ${ }^{4}$ The human enzyme shares $85 \%$ sequence identity with both the rabbit P450 4B1 and mouse P450 4b1 enzymes (www.uniprot.org). Native human P450 4B1 has currently not been heterologously expressed or purified to our knowledge, although a modified version was expressed recently. 5 The P450 4B1 heme prosthetic group is covalently bound to Glu-310, a phenomenon shared with other P450 Family 4 enzymes. ${ }^{6-8}$ Crystal structures of rabbit P450 4B1 clearly show this covalent binding of the heme, holding the prosthetic group in place as well as allowing heme distortion in non-planar conformations. ${ }^{9}, 10$

Drug-induced oxidative stress and its involvement in toxicity have been studied for over 60 years. ${ }^{11} \mathrm{P} 450$ enzymes have been implicated in the production of reactive oxygen species (ROS) through abortive reaction cycles. ${ }^{12} \mathrm{P} 450$ enzymes can also be redox targets, in that most P450s are anchored to the cytosolic side of the endoplasmic reticulum (ER) membrane. Compared with mitochondria, the ER lumen has a higher oxidizing potential, which is required for disulfide bond formation and other oxidative processes. ${ }^{13}$ This oxidative potential is usually controlled in the lumen by small molecules (ascorbate and glutathione) and proteins (Erola, protein disulfide isomerase). When this buffering network is perturbed, ROS can modify proteins in close proximity to the ER lumen. Such protein modification, e.g. cysteine oxidation, can signal a stress response to correct the homeostatic imbalance. ${ }^{14}$

One such oxidative protein modification, cysteine-sulfenic acid, has a relatively short halflife in proteins. ${ }^{15}$ This modification has been implicated in both inhibition and activation of enzymes, also functioning as a reduction-oxidation (redox) sensor in proteins. ${ }^{16}$ Due to both the importance and short-lived nature of sulfenic acids, molecular dynamics (MD) simulations have been employed to study the mechanism of action. Simulations performed on epidermal growth factor receptor ${ }^{17}$ and glyceraldehyde 3 -phosphate dehydrogenase ${ }^{18}$ 
helped elucidate key residues involved in the stability of the sulfenic acid or the reactivity of the modified cysteine. Recently Src kinase was found to be activated by sulfenic acid formation, and the mechanism was revealed by the use of MD. ${ }^{19}$

Recently we showed that the heme-thiolate cysteine of human P450 4A11 was partially sulfenylated (-SOH). ${ }^{20}$ Further analysis with P450 4A11 indicated that preincubation with $\mathrm{H}_{2} \mathrm{O}_{2}$ inhibited catalytic activity, which was inversely correlated with sulfenic acid formation. Examination of other mouse and human P450s showed that heme-thiolate sulfenic acid formation is prevalent among drug-metabolizing microsomal enzymes, including mouse P450 4b1. ${ }^{21}$ Among human P450s 1A2, 2C8, 2C9, and 3A4, only P450 $1 \mathrm{~A} 2$ was insensitive to oxidative inhibition and heme-thiolate sulfenic acid formation. P450s $2 \mathrm{C} 8,2 \mathrm{D} 6$, and $3 \mathrm{~A} 4$ were sensitive to both $\mathrm{H}_{2} \mathrm{O}_{2}$-dependent inhibition and heme-thiolate oxidation. These findings led to the hypothesis that some $\mathrm{P} 450$ enzymes are redox regulated in vivo, while others (e.g., $\mathrm{P} 450$ 1A2) are not. This phenomenon may contribute to observed disease-drug interactions in which decreased clearance of P450 substrates is observed in the presence of inflammatory diseases such as influenza and autoimmune diseases. P450 transcriptional downregulation is known to occur during inflammatory insults, ${ }^{22}$ but hemethiolate sulfenylation may provide a much faster inhibitory mechanism for active proteins during acute inflammatory events, as shown for P450 nitrosylation.

The goal of the present work was to elucidate the basis of the differential redox sensitivity recently discovered in P450 enzymes. ${ }^{20,} 21$ MD simulations were used in conjunction with a recently reported crystal structure of rabbit P450 4B1, used as a model to test the stability of a heme-thiolate sulfenic acid. ${ }^{9}, 10 \mathrm{Gln}-451$ was identified as having a potential role in conferring redox sensitivity in $\mathrm{P} 450$ 4B1, in the context of its interactions with neighboring amino acids, and the resulting hypothesis was tested using site-directed mutagenesis.

\section{MATERIALS AND METHODS}

\section{Materials.}

The rabbit P450 4B1 plasmid (4B1 sequence \#1) ${ }^{23}$ was a generous gift from Prof. Allan Rettie (Univ. Washington, Seattle). $\left[1-{ }^{14} \mathrm{C}\right]$-Lauric acid was obtained from American Radiolabeled Chemicals (St. Louis, MO), nickel-nitrilotriacetic acid (Ni-NTA) agarose was purchased from Qiagen (Redwood City, CA), hydroxylapatite agarose was obtained from Bio-Rad (Hercules, CA), and L- $\boldsymbol{a}$-dilauroyl-sn-glycero-3-phospocholine (DLPC) was obtained from Enzo Life Sciences (Farmingdale, NY). All other reagents were obtained from either Sigma Aldrich or Fisher Scientific.

\section{Site-Directed Mutagenesis.}

The rabbit P450 4B1 cDNA was used as the template to perform site-directed mutagenesis. ${ }^{23}$ The QuikChange Lightning Site-Directed Mutagenesis Kit (Agilent Technologies) was used to mutate Gln- 451 to either a glutamate or a leucine. The resulting mutant genes were subjected to nucleotide sequence analysis to verify mutations. 


\section{Enzyme Expression and Purification.}

Rabbit P450 4B1 (wild-type WT) and the Q451E and Q451L mutants were expressed and purified as previously described, with some modifications. ${ }^{9}$ The supernatant was rolled overnight in $10 \mathrm{~mL}$ of Ni-NTA resin that had been pre-equilibrated with $50 \mathrm{mM}$ potassium phosphate buffer (pH 7.4) containing 20\% glycerol (v/v). Both P450 4B1 (WT) and the Q451E mutant were eluted using the corresponding elution buffer $(500 \mathrm{mM}$ potassium phosphate, $\mathrm{pH} 7.4$, containing $0.06 \%$ sodium cholate (w/v), $20 \%$ glycerol (v/v), $0.5 \mathrm{mM}$ phenylmethyl sulfonyl fluoride (PMSF), $100 \mathrm{mM}$ histidine, and $0.3 \mathrm{mM}$ octane) with the addition of $200 \mathrm{mM}$ imidazole. The Q451L mutant eluted with a low concentration of histidine $(500 \mathrm{mM}$ potassium phosphate buffer ( $\mathrm{pH} 7.4$ ) containing $0.06 \%$ sodium cholate (w/v), 20\% glycerol (v/v), $0.5 \mathrm{mM}$ PMSF, $10 \mathrm{mM}$ histidine, and $0.3 \mathrm{mM}$ octane). All buffers that were used for the hydroxylapatite column had a final concentration of $50 \mu \mathrm{M}$ EDTA (to avoid interaction with the $\mathrm{Ca}^{2+}$ ). Enzymes were stored in $100 \mathrm{mM}$ potassium HEPES buffer (pH 7.4) containing $50 \mathrm{mM}$ potassium acetate, $20 \%$ glycerol (v/v), $0.5 \mathrm{mM}$ EDTA, and 100 $\mu \mathrm{M}$ dithiothreitol (DTT).

The specific content of P450 in the WT P450 4B1 preparation was $5.6 \mathrm{nmol} \mathrm{P450} \mathrm{(mg}$ protein), ${ }^{-1}$ as calculated based by determination of protein with a bicinchoninic acid (BCA) assay (ThermoFisher, using the manufacturer's directions and bovine serum albumin as a standard). The protein migrated as a single major band (50 kDa) in SDS-polyacrylamide gel electrophoresis. With WT P450 4B1 and both of the mutants, the measured P450 concentration was slightly higher that the heme content determined using a pyridine hemochromagen assay. ${ }^{24}$

HPLC analysis of WT P450 4B1 and the Q451L and Q451E mutants ${ }^{25}$ (Jupiter $300 \AA$ C4 column, $4.6 \mathrm{~mm} \times 250 \mathrm{~mm}, 5 \mu \mathrm{m}, 30 \%$ solvent $\mathrm{A}\left(0.1 \% \mathrm{CF}_{3} \mathrm{CO}_{2} \mathrm{H}\right.$ in $\left.\mathrm{H}_{2} \mathrm{O}\right)$ to $50 \%$ solvent $\mathrm{B}\left(0.1 \% \mathrm{CF}_{3} \mathrm{CO}_{2} \mathrm{H}\right.$ in $\left.\mathrm{CH}_{3} \mathrm{CN}\right)$ gradient (v/v) over 5 min, holding at $50 \%$ solvent $\mathrm{B}$ for 1.5 $\mathrm{min}$, and finally $50-100 \%$ solvent $\mathrm{B}$ over $2.5 \mathrm{~min}$, flow $1.5 \mathrm{~mL} \mathrm{~min}^{-1}$ ) showed that $>98 \%$ of the $A_{400}$ trace integral was associated with the protein ( $t_{\mathrm{R}} 9.9 \mathrm{~min}$ ) and $<1 \%$ co-migrated with a hemin standard $\left(t_{\mathrm{R}} 6.0 \mathrm{~min}\right)$. In a control assay with $\mathrm{P} 4503 \mathrm{~A} 4^{26}>98 \%$ of the heme was dissociated form the protein under the same conditions (data not presented). We conclude that, as in previous reports with other 4A Family P450s,, 25 essentially all of the heme was covalently attached to the protein irrespective of the amino acid at position 451 .

\section{Enzymatic Assays.}

Assays were done as previously described, with some modifications. ${ }^{27}$ Incubations for P450 4B1 (WT) and the Q451L mutant generally included $0.2 \mu \mathrm{M}$ P450, $0.4 \mu \mathrm{M}$ NADPH-P450 reductase, $0.4 \mu \mathrm{M}$ cytochrome $b_{5}\left(b_{5}\right), 150 \mu \mathrm{M}$ DLPC, $100 \mathrm{mM}$ potassium phosphate buffer (pH 7.4), $300 \mu \mathrm{M}$ lauric acid, and the indicated amount of $\left[1-{ }^{14} \mathrm{C}\right]$-lauric acid in a final volume of $0.5 \mathrm{~mL}$. Following temperature equilibration to $37^{\circ} \mathrm{C}$ for 5 minutes, reactions were initiated by the addition of an NADPH-regenerating system consisting of $0.5 \mathrm{mM}$ $\mathrm{NADP}^{+}, 10 \mathrm{mM}$ glucose 6-phosphate, and $1 \mathrm{IU} \mathrm{mL}^{-1}$ yeast glucose 6-phosphate dehydrogenase. ${ }^{28}$ Reactions proceeded at $37{ }^{\circ} \mathrm{C}$ for 15 minutes before quenching with 2.0 $\mathrm{mL}$ of methyl tert-butyl ether (MTBE) containing $0.1 \% \mathrm{CH}_{3} \mathrm{CO}_{2} \mathrm{H}(\mathrm{v} / \mathrm{v})$, followed by mixing using a vortex device. The samples were then centrifuged $(2,000 \times g$ for $5 \mathrm{~min})$, and 
$1.8 \mathrm{~mL}$ of the organic layer (upper phase) was transferred to a new glass tube, using a graduated glass pipette, and the solvent was evaporated under an $\mathrm{N}_{2}$ stream.

Incubations with the Q451E mutant were completed following the same procedure, with minor modifications to compensate for the lower catalytic activity. The $\mathrm{P} 450$ concentration was increased to $0.7 \mu \mathrm{M}$, the NADPH-P450 reductase concentration was $1.4 \mu \mathrm{M}$ (to maintain the same P450/NADPH-P450 reductase ratio), and the total reaction volume was increased to $1.0 \mathrm{~mL}$. Reactions were terminated with $4.0 \mathrm{~mL}$ of MTBE, and $3.6 \mathrm{~mL}$ of the organic layer was evaporated under an $\mathrm{N}_{2}$ stream.

The dried extracts were dissolved in $125 \mu \mathrm{L}$ of a 1:1 (v:v) mixture of $\mathrm{H}_{2} \mathrm{O}: \mathrm{CH}_{3} \mathrm{CN}$ containing $0.1 \% \mathrm{CH}_{3} \mathrm{CO}_{2} \mathrm{H}(\mathrm{v} / \mathrm{v})$. The samples were directly injected into a HPLC-/UV/inline liquid scintillation counting system (IN/US Systems). The reaction products were resolved on a Zorbax RX-C8 octylsilane column $(4.6 \mathrm{~mm} \times 250 \mathrm{~mm}, 5 \mu \mathrm{m})$ with mobile phase solvent mixtures A $\left(95 \% \mathrm{H}_{2} \mathrm{O}, 5 \% \mathrm{CH}_{3} \mathrm{OH}, 0.1 \% \mathrm{CH}_{3} \mathrm{CO}_{2} \mathrm{H}, \mathrm{v} / \mathrm{v} / \mathrm{v}\right)$ and $\mathrm{B}(99 \%$ $\left.\mathrm{CH}_{3} \mathrm{OH}, 1 \% \mathrm{H}_{2} \mathrm{O}, 0.1 \% \mathrm{CH}_{3} \mathrm{CO}_{2} \mathrm{H}, \mathrm{v} / \mathrm{v} / \mathrm{v}\right)$. The column was used at ambient temperature. An increasing linear gradient was used (flow rate $1.0 \mathrm{~mL} \mathrm{~min}^{-1}$ ) from $35 \%-100 \% \mathrm{~B}(\mathrm{v} / \mathrm{v}$ ) over $12 \mathrm{~min}$ followed by $100 \% \mathrm{~B}$ for an additional $5 \mathrm{~min}$. The scintillation fluid (Liquiscint ${ }^{\mathrm{TM}}$, National Diagnostics, Atlanta, GA) flow rate was $3.0 \mathrm{~mL} \mathrm{~min}^{-1}$. The reaction products were quantified by radiochromatogram peak areas using the $\beta$-RAM software (Laura $^{\mathrm{TM}}$, LabLogic Systems, Brandon, FL). Concentrations of $\omega$ - and $\omega-1$ hydroxylaurate were calculated by using the ratio of total peak area to product peak area and comparing the resulting ratio to the initial substrate concentration. Rates were expressed as nmol of product formed per nmol P450 in the reaction in 15 minutes. Inhibition plots were plotted with GraphPad Prism (GraphPad, La Jolla, CA).

\section{Protein Oxidation with $\mathrm{H}_{2} \mathrm{O}_{2}$.}

Protein oxidation was performed as previously described. ${ }^{20,21}$

\section{Isotope-Coded Dimedone/lododimedone (ICDID) Labeling of Recombinant P450 4B1.}

ICDID was performed as previously described. ${ }^{20,21}$

\section{Molecular Dynamics Simulations.}

The atomic coordinates of protein and heme were obtained from the crystal structure of cytochrome P450 4B1 (PDB ID: 5T6Q). ${ }^{9}$ Initially, the forcefield parameters of sulfenic acid and sulfenate-containing cysteines were generated using the VMD Force Field Toolkit ${ }^{29}$ and Gaussian09 (Supplemental Text File). ${ }^{30}$

Missing residues (196-200, 272-276) in the protein were modeled as loops using Modeller ${ }^{31}$ and MMTSB Tool Set. ${ }^{32} \mathrm{~A}$ total of nine complexes of protein and heme were built for the simulations: three for CyS548 (Cys-S ${ }^{-}, \mathrm{Cys}_{-} \mathrm{SO}^{-}, \mathrm{Cys}-\mathrm{SOH}$ ); $\mathrm{Gln}-451$ of each complex was mutated to either Glu or Leu using $\mathrm{VMD}^{33}$ or remained as WT. These complexes were then solvated in a $100 \AA \times 100 \AA \times 100 \AA$ cubic box containing 28,356 transferable intermolecular potential with 3-point (TIP3P) waters. Next, systems were neutralized by adding $\mathrm{Na}^{+}$and $\mathrm{Cl}^{-}$ions with a concentration of $0.15 \mathrm{M}$ (Supporting Information Figure 
S1). All systems were subjected to minimization for 10,000 steps, heating to $310 \mathrm{~K}$, and equilibration for $10 \mathrm{~ns}$. A $50 \mathrm{~ns}$ production run for each system was performed using NAMD,${ }^{34}$ the CHARMM 36 force field, ${ }^{35}$ a time step of 2 fs, the SHAKE algorithm, ${ }^{36}$ and the Particle Mesh Ewald ${ }^{37}$ method. Constant temperature and pressure were maintained at $310 \mathrm{~K}$ and $1 \mathrm{~atm}$ using Langevin dynamics and the Nosé-Hoover Langevin piston method, respectively, during the simulation. ${ }^{38}$ Trajectories were saved every 20 ps. Figures 1, 3, 4, S1, and S2 and movies were rendered using VMD. Figures 2, S3, S5, and S6 were generated using Gnuplot (www.gnuplot.info). The root mean square deviation (RMSD, Figure S3), F441-Q451 distance (Figure 2A-C), and the dihedral angles ( $\phi, \psi$, Figures S5, S6) were calculated using VMD software. The solvent accessible surface areas (SASA, Figure 2D-F) were computed using the built-in SASA functions in VMD, which implements the ShrakeRupley algorithm. ${ }^{39}$ All analyses were performed using the last $40 \mathrm{~ns}$ of the production run.

\section{RESULTS and DISCUSSION}

\section{Generation of Sulfenic Acid and Sulfenate Cysteine Amino Acids.}

We initially modeled sulfenate- and sulfenic acid-containing cysteines (Supporting Information Figure S1). The charge distribution calculated for the sulfenic acid corresponded well with a previously produced topology file for the program Amber. ${ }^{40} \mathrm{To}$ our knowledge, a forcefield has not been produced for a cysteine sulfenate amino acid. The sulfenate was constructed because of the possibility that the negative charge could coordinate with the heme iron. Recent studies with dipeptides have suggested that the $\mathrm{p} K_{\mathrm{a}}$ values of sulfenic acids are much closer to the physiological $\mathrm{pH}$ range than previously measured in small molecules (5.9-7.2). ${ }^{41-44}$

\section{GIn-451 Displays Open and Closed Conformations in the Presence of Cys-S- and Cys-SOH Heme Ligands, Respectively.}

In order to determine the effect of sulfenylation on the heme-thiolate cysteine, we performed MD simulations on rabbit P450 4B1. Three 40-ns MD simulations were initially performed using P450 4B1 with either the heme-thiolate $\left(\mathrm{Cys}^{-} \mathrm{S}^{-}\right)$, sulfenic acid (Cys-SOH), or sulfenate (Cys- $\mathrm{SO}^{-}$) form of the Cys-448 residue (Figure 1). To directly study the region surrounding the heme-thiolate cysteine, we restrained portions of the enzyme extraneous to the proximal heme-thiolate region (Supporting Information Figure S2). This procedure allowed for minimal distortion and a low deviation in RMSD of the enzyme (Supporting Information Figure S3). This initial distortion may be due to the lack of a simulated membrane system. The analysis revealed several interesting phenomena. Cys- $\mathrm{S}^{-}$periodically interacted with the backbone amide nitrogen of Gln-451 (Figure 1B, Supporting Information Movie 1). Additionally, the Gln-451 carboxamide hydrogens were hydrogen-bonded to the backbone amide oxygens of Phe-140, Thr-137, and Ile-449 in both the Cys-S ${ }^{-}$and $\mathrm{Cys}_{-} \mathrm{SO}^{-}$ simulations (Figure 1A and 1C, respectively). The Cys-448 sulfenic acid (Cys-SOH) consistently formed hydrogen bonds with the heme-nitrogen atoms of the porphyrin ring (Figure 1D, Supporting Information Movie 2). Moreover, Gln-451 flipped out of the hydrogen-bound conformation (Figure 1A) to contribute to an NH- $\pi$ bond with Phe-441 (Figure 1D). These "open" and "closed" conformations alter the solvent accessibility of the heme-thiolate Cys-448. The distance between the Gln-451 carboxamide and Phe-441 was 
examined over the length of the $40 \mathrm{~ns}$ simulation for each of the cysteine residues (Figure $2 \mathrm{~A})$. The reduced thiolate enzyme maintained a greater distance between the two residues and the oxidized Cys-448 sulfenic acid adopted a closed conformation between Gln- 451 and Phe-441, indicating that the different conformations Gln-451 adopted when Cys-448 is either oxidized or reduced may confer redox sensitivity in the enzyme. The Cys-SO ${ }^{-}$ simulation revealed an open conformation that was more stable than the Cys- $\mathrm{S}^{-}$simulation (Figure 2A). This behavior is also apparent in the Ramachandran plots of Gly-450 and Gln-451, which show changes in the $\varphi / \psi$ angles dependent on the oxidation state of Cys-448 (Supporting Information Figures S5 and S6).

In an open conformation, Gln-451 can allow for greater solvent exposure of the hemethiolate cysteine and thus permit more frequent interactions with oxidizing agents, as visualized in the SASA calculations of Cys-448 (Figure 2D). The heme-thiolate periodically interacted with the backbone amide nitrogen, indicating that the iron sulfur ligand may break occasionally, allowing for interaction with oxidizing agents. This pattern has been noted previously with the enzyme nitrile hydratase, where a coordinated sulfenic acid is involved in the catalytic step of the enzyme. ${ }^{45}$ Although the solvent accessibility is higher in the closed conformation (i.e., seen with the Cys-SOH MD simulation), Gln-451 may protect the oxidized cysteine from solvent to allow for extended stability, as indicated by SASA calculations (Figure 2D). Additionally, in the sulfenic acid form, the number of waters within $5 \AA$ of the Cys-448 sulfur was greatly reduced compared to the thiolate, further suggesting a protective effect of Gln-451 (Supporting Information Figure S4A). The NH- $\pi$ bond formed between Gln- 451 and Phe- 441 may additionally confer more stability. Both crystal structures of P450 4B1 showed interactions between Gln-451 and Phe-441 with the heme-thiolate entity. 9 , 10

\section{Mutations in GIn-451 Alter Conformations Observed in WT P450 4B1.}

Gln-451 was mutated in silico to either a leucine (Q451L) or a glutamate (Q451E). In six additional $40 \mathrm{~ns}$ MD simulations for the mutants, both mutations altered the Gln-451X:Phe-441 distance (closed and open conformations) (Figures 2B, 2C) and SASA of Cys-448 (Figures 2E, 2F) noted in the wild type enzyme. With both mutations, the sulfenate (Cys-448 $\mathrm{SO}^{-}$) showed a closed conformation between residue 451 and Phe-441 and a decreased SASA of Cys-448 with respect to the thiolate. Additionally, the sulfenic acid (Cys-448 SOH) increased the distance distribution between residue 451 and Phe-441 and altered the SASA of Cys-448. These differences in the SASA can be further exemplified in the differences in the number of water molecules within $5 \AA$ of the Cys- 448 sulfur, which is reduced in both mutant enzymes when the Cys- $448 \mathrm{SO}^{-}$oxidation is modeled (Supporting Information Figure S4B and C).

Closer examination of the P450 4B1 Q451E mutant showed that Glu-451 participates in Hbonds with surrounding water molecules (Figure 3A). Throughout the Q451E simulation the sulfenate oxygen of Cys-448 contributed to an H-bond with the backbone amide nitrogen of Q451E, restraining the carboxylate to a closed conformation (Figure 3B). However, in the Cys-SOH Q451E simulation, Glu-451 interacted mainly with Gln-452 and not Phe-441, 
leaving Cys-448 more exposed (Figure 3C). This phenomenon could presumably alter solvent interactions and reduce stability of the sulfenic acid modification (Figure 2E).

The Q451L mutant contributed to more hydrophobic interactions with residues surrounding the heme region. During the Cys-S - simulation, Leu-451 interacted with Tyr-142 in an open conformation (Figure 4A). As in the Q451E mutant, the Cys-448 SO${ }^{-}$oxygen stably interacted with the amide nitrogen of Leu-451, in a closed conformation (Figure 4B). The Cys-SOH simulation also revealed a hydrophobic interaction between Leu-451 and Phe-441 (Figure 4C).

Mutation of Gln-451 to either a leucine or glutamate allowed P450 4B1 to adopt differing conformations. This behavior is also apparent in the Ramachandran plots of Gly-450 and Gln-451, which show differences in the $\varphi / \psi$ angles compared to the WT enzyme (Supporting Information Figures S5 and S6, respectively). Q451E simulations indicated that the glutamate mostly interacted with surrounding water molecules and not with other residues of the protein, as in the case of Gln-451. The distance between Q451E and Phe-441 grew shorter and the SASA decreased in the Cys-S ${ }^{-}$simulation, suggesting more protection of the thiolate ligand. The Q451E-Phe-441 distance was greater in the Cys-SOH compared to the WT enzyme, indicating greater solvent exposure for the sulfenic acid, conferring lower stability. Cys-SO ${ }^{-}$decreased the Q451X-F441 distance as well, potentially allowing for a shift in stability.

\section{GIn-451 Mutations Abrogate Redox Sensitivity Observed in WT P450 4B1.}

The Q451L and Q451E proteins were produced and oxidative inhibition assays were performed in vitro (Figure 5). The P450 4B1 WT enzyme was inhibited approximately 80\% after preincubation with $1 \mathrm{mM} \mathrm{H}_{2} \mathrm{O}_{2}$ (Figure $5 \mathrm{~A}$ ). Both mutants showed little sensitivity to $\mathrm{H}_{2} \mathrm{O}_{2}$, i.e. P450 4B1 Q451L and Q451E both showed $<20 \%$ loss of activity following preincubation with $1 \mathrm{mM} \mathrm{H}_{2} \mathrm{O}_{2}$ (Figure 5B, 5C). In addition to corroborating the MD simulation prediction, this modulation of redox sensitivity in $\mathrm{P} 4504 \mathrm{~B} 1$ indicates that the surrounding microenvironment around the heme-thiolate cysteine is important in regulating heme-thiolate exposure to solvent and redox sensitivity.

In addition to a decrease in the redox sensitivity for the P450 4B1 mutants, a significant decrease in overall catalytic activity was also noted for the Q451E mutant. This amino acid change altered the environment around the heme-thiolate ligand by introducing a negative charge. Despite the reduction in activity, both Q451E and Q451L produced typical CObinding spectra (Supporting Information Figure S7).

\section{Heme-thiolate Sulfenylation is Reduced in GIn-451 Mutants.}

ICDID labeling revealed that the WT P450 4B1 enzyme was sulfenylated to a degree concomitant with the loss of activity ( 60\%) (Figure 6). Very little dimedone labeling was observed in either the Q451L or Q451E mutants, indicating that the heme-thiolate ligand remained intact. 


\section{CONCLUSIONS}

In summary, Gln-451 of rabbit P450 4B1 is involved in the redox sensitivity observed on the catalytic activity of the enzyme. Mutation to either a leucine or glutamate abrogated both heme-thiolate sulfenylation and $\mathrm{H}_{2} \mathrm{O}_{2}$-dependent inhibition. The position of Gln-451 ( $\mathrm{n}+3$ to the conserved heme-thiolate cysteine) is overrepresented in P450s, as well as glutamate, methionine, and lysine (Figure 7) ${ }^{46}$ The consensus sequence of P450s surrounding the heme-thiolate cysteine (Phe-X-X-Gly-X-Arg-X-Cys-X-Gly) is highly conserved. ${ }^{47}$ This sequence includes Phe-441 in P450 4B1 (n-7 from the heme-thiolate cysteine), which interacts with Gln-451. The phenylalanine residue at this position is highly conserved throughout most P450 enzymes (Figure 7). This residue was not mutated because there is substantial evidence that the phenylalanine contributes to heme loading and electron transfer. ${ }^{48-51}$ Despite being consistent among human P450 enzymes, the " $X$ " positions in the consensus sequence are more variable. This work suggests that these variable positions alter stability of the heme and redox sensitivity. Previous mutations in the proximal heme region have shown differences in the electronic aspects of the catalytic cycle. ${ }^{52,53}$ Interestingly, P450 1A2, which was previously shown to be redox insensitive, contains a glutamate at the $\mathrm{n}+3$ position to the heme-thiolate cysteine but $\mathrm{P} 450 \mathrm{~s} 2 \mathrm{C} 8$ and $2 \mathrm{D} 6$ also have glutamate at this position (and are redox sensitive) ${ }^{21}$. This inconsistency suggests that a combination of residues is important in conferring redox sensitivity in individual enzymes. Establishing a consensus sequence that confers redox sensitivity will ultimately allow for predictive guides for P450 sensitivity. Developing a consensus sequence would require testing a larger diversity of P450 enzymes for redox sensitivity.

Sulfenylation of the heme-thiolate may allow the cell to temporarily inactivate P450 enzymes during oxidative cellular onslaughts. Disabling these enzymes would allow for a higher availability of reducing equivalents (i.e., NADPH) for proteins involved in redox homeostasis. This could also limit the production of more bioactive metabolites that may contribute to perturbations in redox homeostasis.

The recent findings indicate that P450 enzymes are redox regulated; however, this phenomenon has yet to be tested in vivo or in cellulo. ${ }^{20,21}$ Proving this hypothesis in vivo would provide insight into the aforementioned drug interactions that have been observed in several disease conditions. ${ }^{22}$ Chemicals that cause drug-induced oxidative stress and toxicity include paraquat, doxorubicin, acetaminophen, and many others, including 4B1 substrates. 2, 54, 55 In this context, the yet unknown endogenous function of 4B1 and its drugmetabolizing ability may be inhibited in inflammatory or oxidative disease states.

\section{Supplementary Material}

Refer to Web version on PubMed Central for supplementary material.

\section{ACKNOWLEDGMENTS.}

The computational resources of the Advanced Computing Center for Research and Education at Vanderbilt University were utilized. All mass spectrometry was performed at the Vanderbilt Mass Spectrometry Resource Core. We thank K. Trisler for assistance in preparation of the manuscript. 
Funding

This work was supported in part by U.S. National Institutes of Health Grant R01 GM118122 (F.P.G.), P01 HL128203 (J.P.S., H.D.S.), and F31 HL136133 (M.E.A.) and American Heart Association Predoctoral Fellowship PRE33410007 (M.E.A.).

\section{ABBREVIATIONS}

$b_{5}$

Cys-S ${ }^{-}$

Cys-SO- $^{-}$

Cys-SOH

DLPC

ER

ICDID

MD

MTBE

P450 (or CYP)

PMSF

redox

RMSD

ROS

SASA

TIP3P

WT cytochrome $b_{5}$

cysteine heme thiolate

cysteine sulfenate

cysteine sulfenic acid

L-a-dilauroyl-sn-glycero-3-phospocholine

endoplasmic reticulum

isotope-coded dimedone/iododimedone

molecular dynamics

methyl tert-butyl ether

cytochrome P450

phenylmethyl sulfonyl fluoride

oxidation-reduction

root mean square deviation

reactive oxygen species

solvent accessible surface area

transferable intermolecular potential with 3 points

wild-type.

\section{REFERENCES}

(1). Guengerich FP (2015) Human cytochrome P450 enzymes, In Cytochrome P450: Structure, Mechanism, and Biochemistry (Ortiz de Montellano PR, Ed.) pp 523-785, Springer, New York.

(2). Baer BR, and Rettie AE (2006) CYP4B1: an enigmatic P450 at the interface between xenobiotic and endobiotic metabolism. Drug Metab. Rev 38, 451-476. [PubMed: 16877261]

(3). Fisher MB, Zheng YM, and Rettie AE (1998) Positional specificity of rabbit CYP4B1 for $\omega$ hydroxylation 1 of short-medium chain fatty acids and hydrocarbons. Biochem. Biophys. Res. Commun 248, 352-355. [PubMed: 9675139]

(4). Choudhary D, Jansson I, Stoilov I, Sarfarazi M, and Schenkman JB (2005) Expression patterns of mouse and human CYP orthologs (families 1-4) during development and in different adult tissues. Arch. Biochem. Biophys 436, 50-61. [PubMed: 15752708]

(5). Roellecke K, Jager VD, Gyurov VH, Kowalski JP, Mielke S, Rettie AE, Hanenberg H, Wiek C, and Girhard M (2017) Ligand characterization of CYP4B1 isoforms modified for high-level 
expression in Escherichia coli and HepG2 cells. Protein Eng. Des. Sel 30, 205-216. [PubMed: 28073960]

(6). Henne KR, Kunze KL, Zheng YM, Christmas P, Soberman RJ, and Rettie AE (2001) Covalent linkage of prosthetic heme to CYP4 family P450 enzymes. Biochemistry 40, 12925-12931. [PubMed: 11669629]

(7). LeBrun LA, Xu F, Kroetz DL, and Ortiz de Montellano PR (2002) Covalent attachment of the heme prosthetic group in the CYP4F cytochrome P450 family. Biochemistry 41, 5931-5937. [PubMed: 11980497]

(8). Ortiz de Montellano PR (2008) Mechanism and role of covalent heme binding in the CYP4 family of P450 enzymes and the mammalian peroxidases. Drug Metab. Rev 40, 405-426. [PubMed: 18642140]

(9). Hsu MH, Baer BR, Rettie AE, and Johnson EF (2017) The Crystal Structure of Cytochrome P450 4B1 (CYP4B1) Monooxygenase complexed with octane discloses several structural adaptations for $\omega$-hydroxylation. J. Biol. Chem 292, 5610-5621. [PubMed: 28167536]

(10). Jennings GK, Hsu MH, Shock LS, Johnson EF, and Hackett JC (2018) Noncovalent interactions dominate dynamic heme distortion in cytochrome P450 4B1. J. Biol. Chem 293, 11433-11446. [PubMed: 29858244]

(11). Gillette JR, Brodie BB, and La Du BN (1957) The oxidation of drugs by liver microsomes: on the role of TPNH and oxygen. J. Pharmacol. Exp. Ther 119, 532-540. [PubMed: 13429461]

(12). Albertolle ME, and Peter Guengerich F (2018) The relationships between cytochromes P450 and $\mathrm{H}_{2} \mathrm{O}_{2}$ : Production, reaction, and inhibition. J. Inorg. Biochem 186, 228-234. [PubMed: 29990746]

(13). Parvez S, Long MJC, Poganik JR, and Aye Y (2018) Redox signaling by reactive electrophiles and oxidants. Chem. Rev 118, 8798-8888. [PubMed: 30148624]

(14). Ochoa CD, Wu RF, and Terada LS (2018) ROS signaling and ER stress in cardiovascular disease. Mol. Aspects Med 63, 18-29. [PubMed: 29559224]

(15). Gupta V, and Carroll KS (2014) Sulfenic acid chemistry, detection and cellular lifetime. Biochim. Biophys. Acta 1840, 847-875. [PubMed: 23748139]

(16). Devarie-Baez NO, Silva Lopez EI, and Furdui CM (2016) Biological chemistry and functionality of protein sulfenic acids and related thiol modifications. Free Radic. Res 50, 172-194. [PubMed: 26340608]

(17). Truong TH, Ung PM, Palde PB, Paulsen CE, Schlessinger A, and Carroll KS (2016) Molecular basis for redox activation of epidermal growth factor receptor kinase. Cell Chem. Biol 23, 837848. [PubMed: 27427230]

(18). Peralta D, Bronowska AK, Morgan B, Doka E, Van Laer K, Nagy P, Grater F, and Dick TP (2015) A proton relay enhances $\mathrm{H}_{2} \mathrm{O}_{2}$ sensitivity of GAPDH to facilitate metabolic adaptation. Nat. Chem. Biol 11, 156-163. [PubMed: 25580853]

(19). Heppner DE, Dustin CM, Liao C, Hristova M, Veith C, Little AC, Ahlers BA, White SL, Deng B, Lam YW, Li J, and van der Vliet A (2018) Direct cysteine sulfenylation drives activation of the Src kinase. Nat. Commun 9, 4522. [PubMed: 30375386]

(20). Albertolle ME, Kim D, Nagy LD, Yun CH, Pozzi A, Savas Ü, Johnson EF, and Guengerich FP (2017) Heme-thiolate sulfenylation of human cytochrome P450 4A11 functions as a redox switch for catalytic inhibition. J. Biol. Chem 292, 11230-11242. [PubMed: 28533430]

(21). Albertolle M, Phan TTN, Pozzi A, and Guengerich FP (2018) Sulfenylation of human liver and kidney microsomal cytochromes P450 and other drug metabolizing enzymes as a response to redox alteration. Mol. Cell. Proteomics 17, 889-900. [PubMed: 29374135]

(22). Coutant DE, and Hall SD (2018) Disease-drug interactions in inflammatory states via effects on CYP-mediated drug clearance. J. Clin. Pharmacol 58, 849-863. [PubMed: 29505093]

(23). Cheesman MJ, Baer BR, Zheng YM, Gillam EM, and Rettie AE (2003) Rabbit CYP4B1 engineered for high-level expression in Escherichia coli: Ligand stabilization and processing of the N-terminus and heme prosthetic group. Arch. Biochem. Biophys 416, 17-24. [PubMed: 12859977]

(24). Omura T, and Sato R (1964) The carbon monoxide-binding pigment of liver microsomes. I. Evidence for its hemoprotein nature. J. Biol. Chem 239, 2370-2378. [PubMed: 14209971] 
(25). Hoch U, and Ortiz de Montellano PR (2001) Covalently linked heme in cytochrome P450 4A fatty acid hydroxylases. J. Biol. Chem 276, 11339-11346. [PubMed: 11139583]

(26). Hosea NA, Miller GP, and Guengerich FP (2000) Elucidation of distinct ligand binding sites for cytochrome P450 3A4. Biochemistry 39, 5929-5939. [PubMed: 10821664]

(27). Kim D, Cha GS, Nagy LD, Yun C-H, and Guengerich FP (2014) Kinetic analysis of lauric acid hydroxylation by human cytochrome P450 4A11. Biochemistry 53, 6161-6172. [PubMed: 25203493]

(28). Guengerich FP (2014) Analysis and characterization of enzymes and nucleic acids relevant to toxicology, In Hayes' Principles and Methods of Toxicology (Hayes AW, and Kruger CL, Eds.) pp 1905-1964, CRC Press-Taylor \& Francis Boca Raton, FL.

(29). Mayne CG, Saam J, Schulten K, Tajkhorshid E, and Gumbart JC (2013) Rapid parameterization of small molecules using the Force Field Toolkit. J. Comput. Chem 34, 2757-2770. [PubMed: 24000174]

(30). Frisch MJ, Trucks GW, Schlegel HB, Scuseria GE, Robb MA, Cheeseman JR, Scalmani G, Barone V, Mennucci B, Petersson GA, Nakatsuji H, Caricato M, Li X, Hratchian HP, Izmaylov AF, Bloino J, Zheng G, Sonnenberg JL, Hada M, Ehara M, Toyota K, Fukuda R, Hasegawa J, Ishida M, Nakajima T, Honda Y, Kitao O, Nakai H, Vreven T, Montgomery JA, Peralta JE, Ogliaro F, Bearpark M, Heyd JJ, Brothers E, Kudin KN, Staroverov VN, Kobayashi R, Normand J, Raghavachari K, Rendell A, Burant JC, Iyengar SS, Tomasi J, Cossi M, Rega N, Millam JM, Klene M, Knox JE, Cross JB, Bakken V, Adamo C, Jaramillo J, Gomperts R, Stratmann RE, Yazyev O, Austin AJ, Cammi R, Pomelli C, Ochterski JW, Martin RL, Morokuma K, Zakrzewski VG, Voth GA, Salvador P, Dannenberg JJ, Dapprich S, Daniels AD, Farkas, Foresman JB, Ortiz JV, Cioslowski J, and Fox DJ. (2009) Gaussian 09, Revision E.01, Wallingford CT.

(31). Webb B, and Sali A (2014) Comparative protein structure modeling using MODELLER. Curr. Protocol. Bioinform 47, 5 1-32.

(32). Feig M, Karanicolas J, and Brooks CL 3rd. (2004) MMTSB Tool Set: Enhanced sampling and multiscale modeling methods for applications in structural biology. J. Mol. Graph. Model 22, 377-395. [PubMed: 15099834]

(33). Humphrey W, Dalke A, and Schulten K (1996) VMD: Visual molecular dynamics. J. Mol. Graph 14, 33-38, 27-38. [PubMed: 8744570]

(34). Phillips JC, Braun R, Wang W, Gumbart J, Tajkhorshid E, Villa E, Chipot C, Skeel RD, Kale L, and Schulten K (2005) Scalable molecular dynamics with NAMD. J. Comput. Chem 26, 17811802. [PubMed: 16222654]

(35). Huang J, and MacKerell AD Jr. (2013) CHARMM36 all-atom additive protein force field: Validation based on comparison to NMR data. J. Comput. Chem 34, 2135-2145. [PubMed: 23832629]

(36). Ryckaert J-P, Ciccotti G, and Berendsen HJ (1977) Numerical integration of the cartesian equations of motion of a system with constraints: molecular dynamics of $n$-alkanes. J. Comput. Physics 23, 327-341.

(37). Darden T, York D, and Pedersen L (1993) Particle mesh Ewald: An N· log (N) method for Ewald sums in large systems. J. Chem. Physics 98, 10089-10092.

(38). Feller SE, Zhang Y, Pastor RW, and Brooks BR (1995) Constant pressure molecular dynamics simulation: The Langevin piston method. J. Chem. Physics 103, 4613-4621.

(39). Shrake A, and Rupley JA (1973) Environment and exposure to solvent of protein atoms. Lysozyme and insulin. J. Mol. Biol 79, 351-371. [PubMed: 4760134]

(40). Defelipe LA, Lanzarotti E, Gauto D, Marti MA, and Turjanski AG (2015) Protein topology determines cysteine oxidation fate: the case of sulfenyl amide formation among protein families. PLoS Comput. Biol 11, e1004051. [PubMed: 25741692]

(41). Gupta V, and Carroll KS (2016) Profiling the reactivity of cyclic C-nucleophiles towards electrophilic sulfur in cysteine sulfenic acid. Chem. Sci 7, 400-415. [PubMed: 26819701]

(42). Nagy P, and Ashby MT (2007) Reactive sulfur species: Kinetics and mechanisms of the oxidation of cysteine by hypohalous acid to give cysteine sulfenic acid. J. Am. Chem. Soc 129, 1408214091. [PubMed: 17939659] 
(43). Okuyama T, Miyake K, Fueno T, Yoshimura T, Soga S, and Tsukurimichi E (1992) Equilibrium and kinetic studies of reactions of 2-methyl-2-propanesulfenic acid. Heteroatom. Chem 3, $577-$ 583.

(44). Portillo-Ledesma S, Randall LM, Parsonage D, Dalla Rizza J, Karplus PA, Poole LB, Denicola A, and Ferrer-Sueta G (2018) Differential kinetics of two-cysteine peroxiredoxin disulfide formation reveal a novel model for peroxide sensing. Biochemistry 57, 3416-3424. [PubMed: 29553725]

(45). Martinez S, Wu R, Sanishvili R, Liu D, and Holz R (2014) The active site sulfenic acid ligand in nitrile hydratases can function as a nucleophile. J. Am. Chem. Soc 136, 1186-1189. [PubMed: 24383915]

(46). O'Shea JP, Chou MF, Quader SA, Ryan JK, Church GM, and Schwartz D (2013) pLogo: A probabilistic approach to visualizing sequence motifs. Nat. Methods 10, 1211-1212. [PubMed: 24097270]

(47). Werck-Reichhart D, and Feyereisen R (2000) Cytochromes P450: A success story. Genome Biol. 1, Reviews3003 3001.

(48). Porter TD (1994) Mutagenesis at a highly conserved phenylalanine in cytochrome P450 2E1 affects heme incorporation and catalytic activity. Biochemistry 33, 5942-5946. [PubMed: 8180223]

(49). Shimizu T (1997) Diverse role of conserved aromatic amino acids in the electron transfer of cytochrome P450 catalytic functions: site-directed mutagenesis studies. Recent Res. Develop. Pure Applied Chem 1, 196-175.

(50). Stayton PS, Poulos TL, and Sligar SG (1989) Putidaredoxin competitively inhibits cytochrome $b_{5}$-cytochrome $\mathrm{P}-450_{\text {cam }}$ association: A proposed molecular model for a cytochrome $\mathrm{P}-450_{\text {cam }}$ electron-transfer complex. Biochemistry 28, 8201-8205. [PubMed: 2690937]

(51). Yang Y, Zhang H, Usharani D, Bu W, Im S, Tarasev M, Rwere F, Pearl NM, Meagher J, Sun C, Stuckey J, Shaik S, and Waskell L (2014) Structural and functional characterization of a cytochrome P450 2B4 F429H mutant with an axial thiolate-histidine hydrogen bond. Biochemistry 53, 5080-5091. [PubMed: 25029089]

(52). Galinato MG, Spolitak T, Ballou DP, and Lehnert N (2011) Elucidating the role of the proximal cysteine hydrogen-bonding network in ferric cytochrome $\mathrm{P}^{450} 0_{\text {cam }}$ and corresponding mutants using magnetic circular dichroism spectroscopy. Biochemistry 50, 1053-1069. [PubMed: 21158478]

(53). Yoshioka S, Tosha T, Takahashi S, Ishimori K, Hori H, and Morishima I (2002) Roles of the proximal hydrogen bonding network in cytochrome P450cam-catalyzed oxygenation. J. Am. Chem. Soc 124, 14571-14579. [PubMed: 12465966]

(54). Deavall DG, Martin EA, Horner JM, and Roberts R (2012) Drug-induced oxidative stress and toxicity. J. Toxicol 2012, 645460. [PubMed: 22919381]

(55). Halliwell B, and Gutteridge JM (2015) Free Radicals in Biology and Medicine. Oxford University Press, Oxford, UK. 

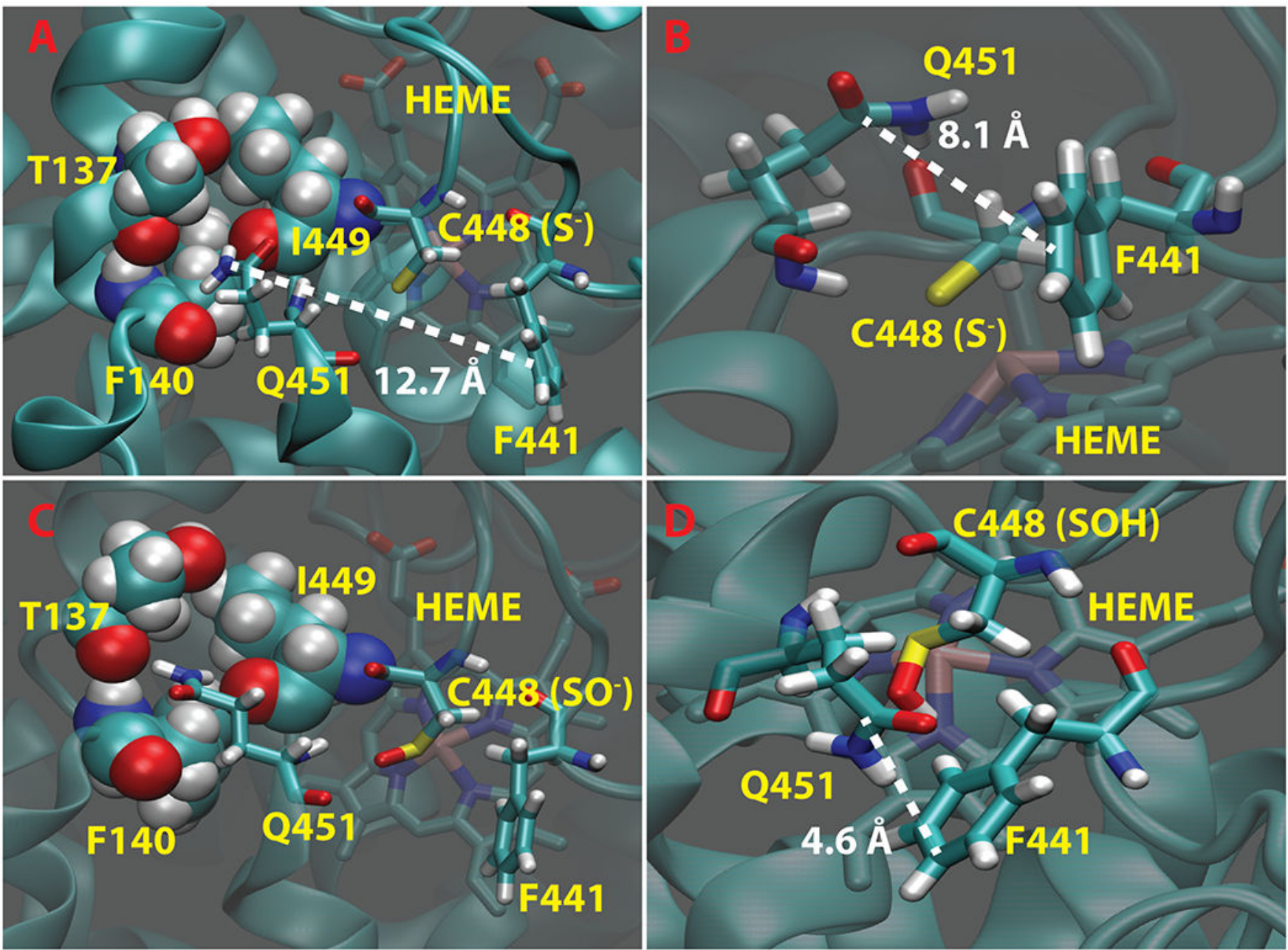

Figure 1. Open, intermediate, and closed conformations in WT P450 4B1.

Binding pocket formed by backbone oxygens of T137, F140, and I449 in an open conformation of (A) Cys-S ${ }^{-}$and (C) Cys-SO ${ }^{-}$. (B) H-bond formed between Q451 and C448 in an intermediate conformation of Cys- $\mathrm{S}^{-}$. (D) H-bond, $\mathrm{NH}-\boldsymbol{\pi}$ interaction of Q451-F441 found in a closed conformation of Cys-SOH. 

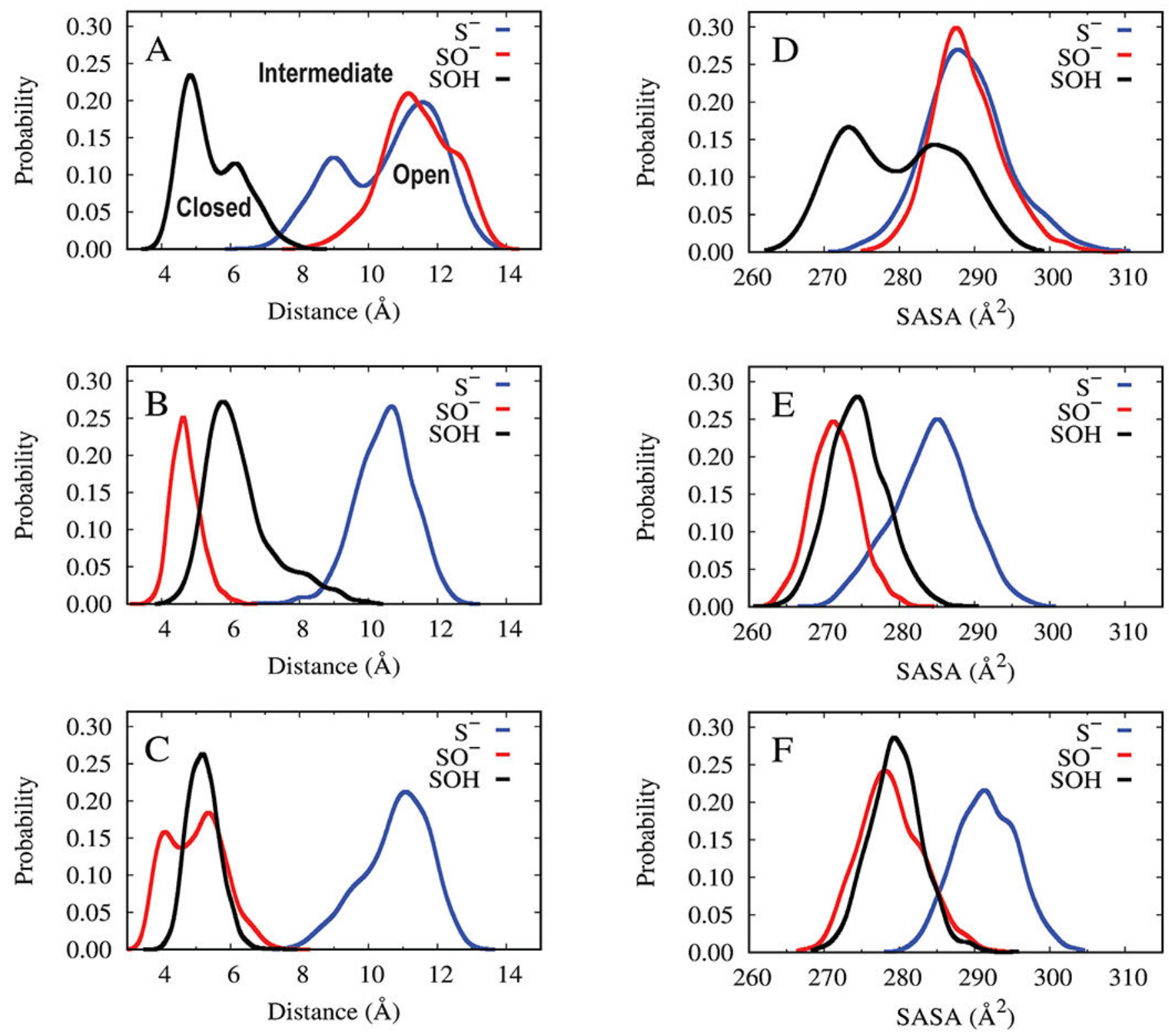

Figure 2. Phe-441-Gln-451 distance and solvent accessible surface area (SASA) of Cys-448. (A) The distance between CZ atom at Phe-441 - CD atom at Gln-451 for WT. (B) The distance between $\mathrm{CZ}$ atom at Phe-441 - CD atom for Q451E. (C) The average distance between CZ atom at Phe-441- CD1 atom at Q451L and CZ atom at Phe-441 - CD2 atom for Q451L. (D) SASA of Cys-448 for WT. (E) SASA of Cys-448 for Q451E. (F) SASA of Cys-448 for Q451L. Data were fitted using Gaussian kernel density estimation. 

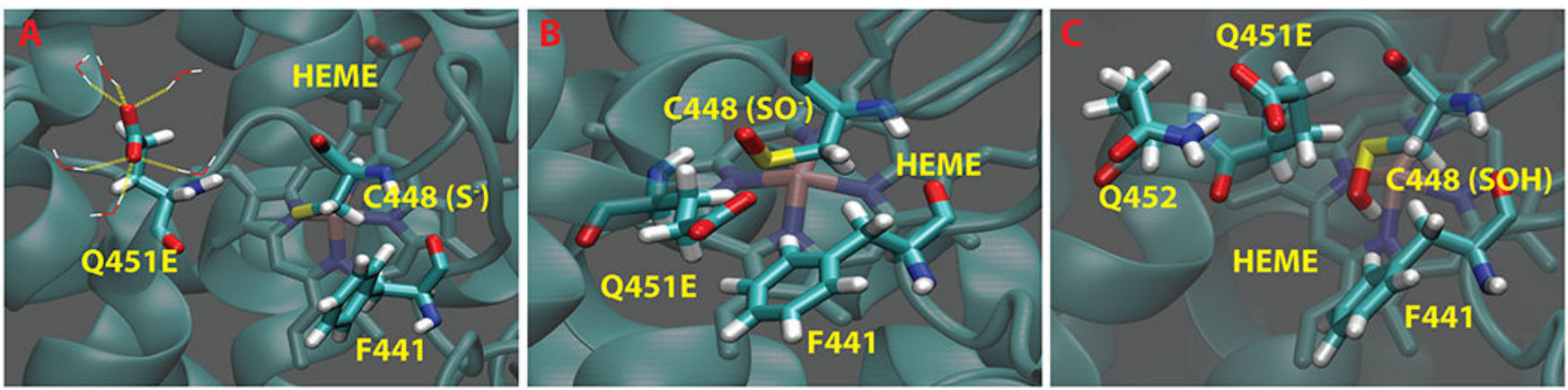

Figure 3. Open and closed conformations in the P450 4B1 Q451E mutant.

(A) H-bonds formed between Q451E and waters in an open conformation of Cys- $\mathrm{S}^{-}$. (B) Hbonds formed between Q451E and Cys-448 in a closed conformation of Cys-SO- ${ }^{-}$. (C) $\mathrm{H}-$ bonds formed between Q451E and Q452 in a closed conformation of Cys-SOH. 

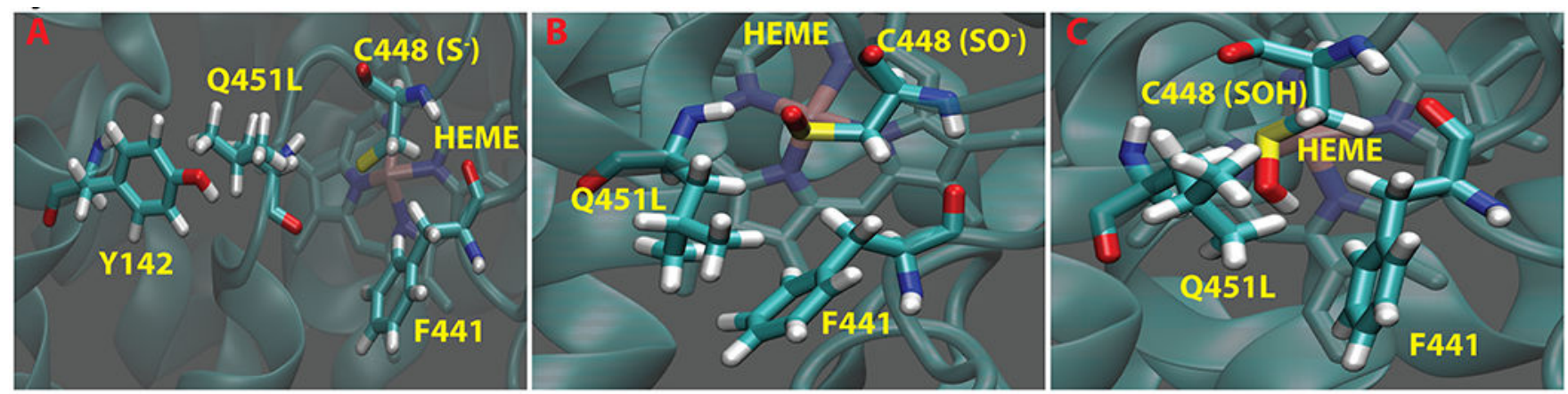

Figure 4. Open and closed conformations in the P450 4B1 Q451L mutant.

(A) Hydrophobic interaction between Q451L and Tyr-142 in an open conformation of Cys-S -. (B) H-bond formed between Q451L and Cys-448 in a closed conformation of Cys-SO'. (C) Hydrophobic interaction between Q451L and Phe-441 in closed conformation of Cys$\mathrm{SO}^{-}$(B) and Cys-SOH (C). 

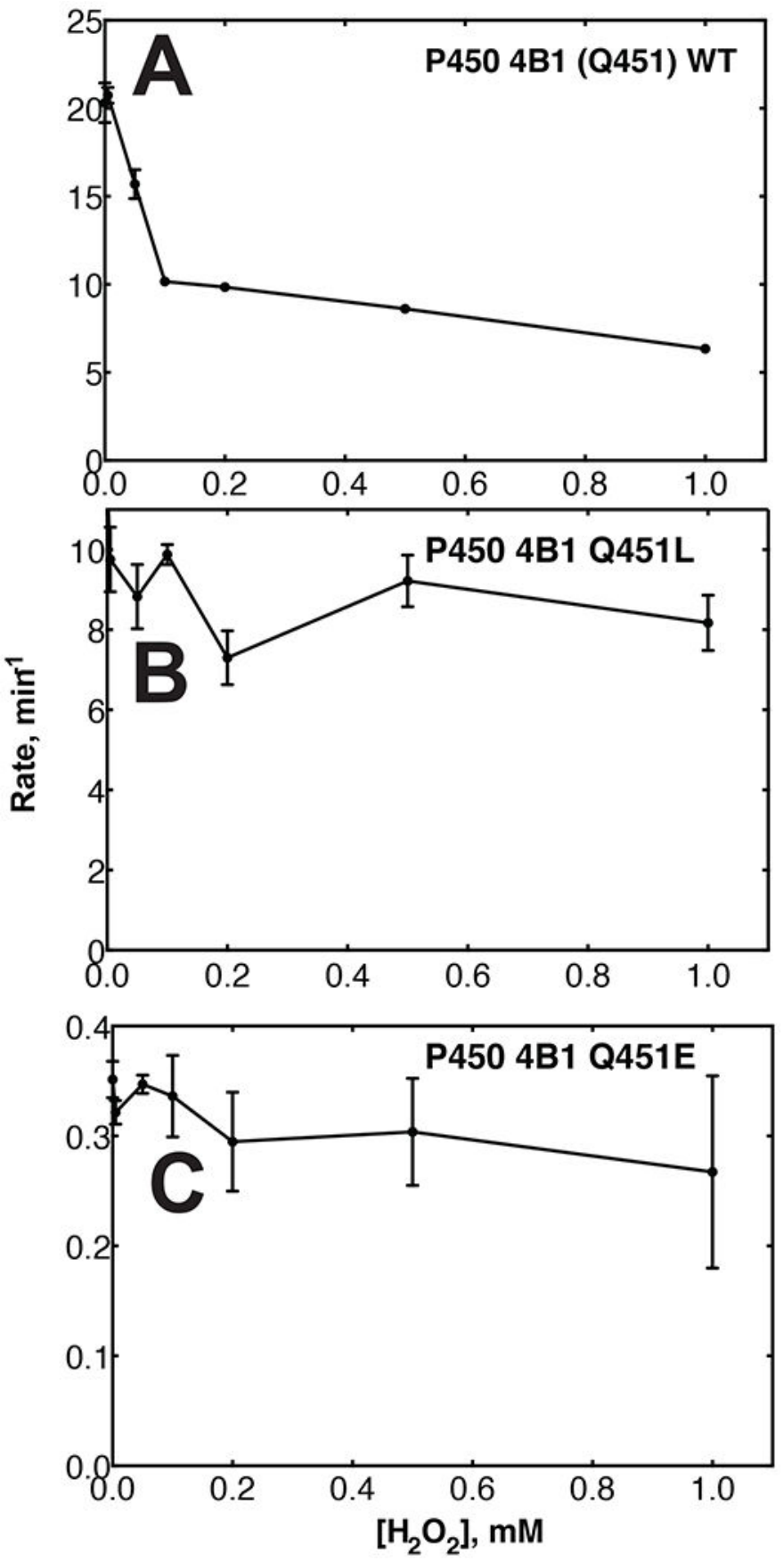

Figure 5. Effect of pre-incubation with $\mathrm{H}_{2} \mathrm{O}_{2}$ on rates of lauric acid $\omega$-hydroxylation. (A) P450 WT; (B) P450 4B1 mutant Q451L; (C) P450 4B1 mutant Q451E. Activity assays were performed in duplicate, with means and range indicated. 


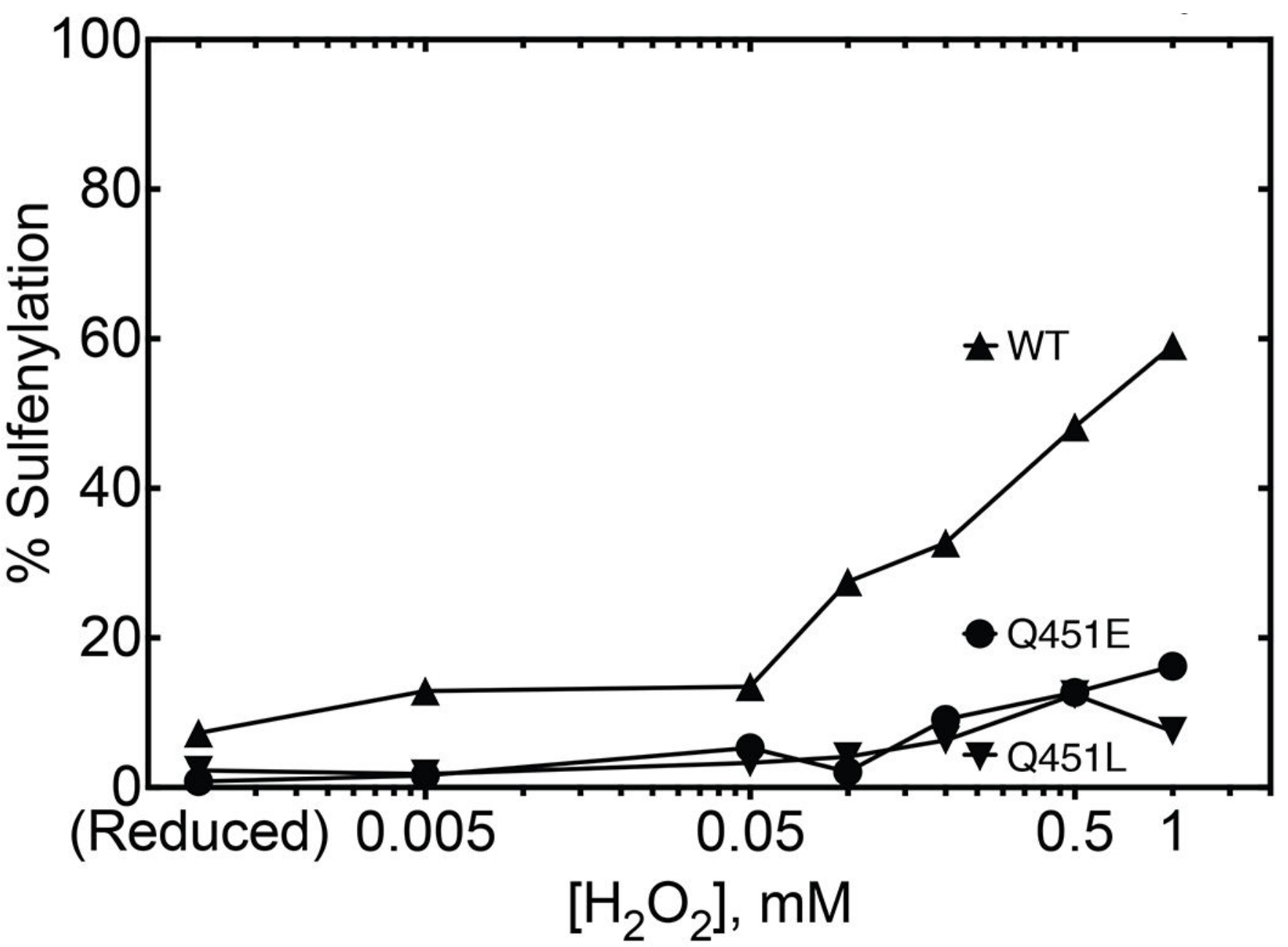

Figure 6.

Effect of pre-incubation with $\mathrm{H}_{2} \mathrm{O}_{2}$ on rates of lauric acid $\omega$-hydroxylation. 


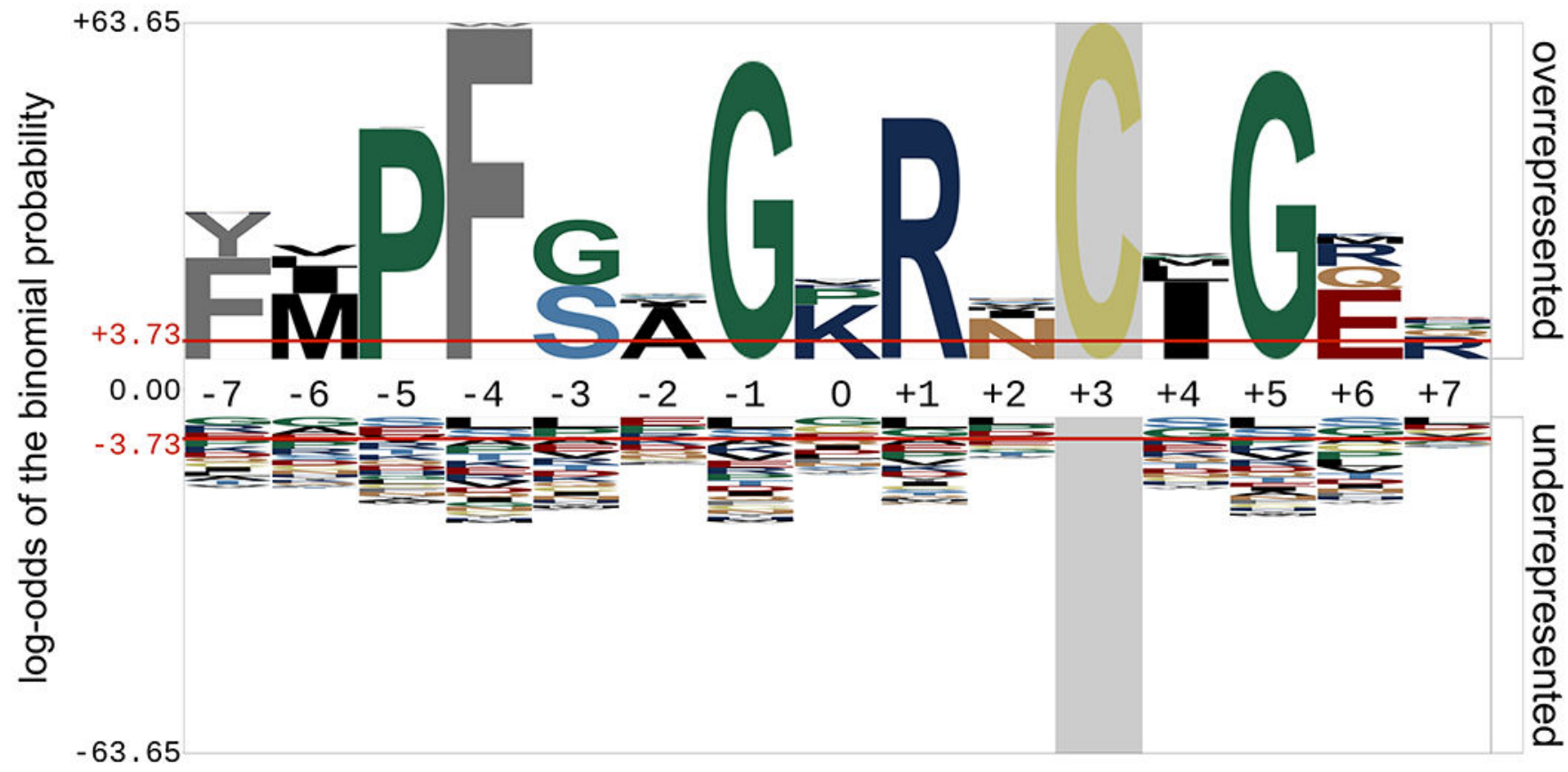

Figure 7. Probability logo of the $\mathbf{P 4 5 0}$ heme-thiolate surrounding consensus sequence.

Amino acid sequences from the 57 human P450 genes were obtained from www.uniprot.org and aligned; probabilities were generated using the full human proteome as a background. This plot was scaled to the height of the heme-thiolate cysteine showing surrounding probabilities of amino acids at specific positions. Plot generated using the program found at plogo.uconn.edu/. 